R. T. King, A. Jostsons, $* *$ and K. Farrell Metals and Ceramics Division

Oak Ridge National Laboratory

Oak Ridge, Tennessee 37830 USA

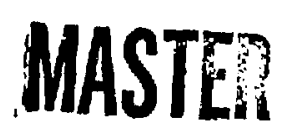

ABSTRACT

A 6061 aluminum alloy target sleeve from the High Flux

Isotope Reactor, originally in' a precipitaion-hardened condition, was examined for neutron radiation damage after exposure to a maximum fast fluence of $9.2 \times 10^{2.2} \mathrm{n} / \mathrm{cm}^{2}(\mathrm{E}>0.1 \mathrm{MeV})$ and a thermal fluence of $1.2 \times 10^{23} \mathrm{n} / \mathrm{cn}^{2}$ at $60^{\circ} \mathrm{C}$. Voids and a transmutation-produced silicon precipitate were found to cause about 1..1\% internal swelling; a surface oxide scale contributed additional swelling. Irradiation-induced strength incraases were measured at test temperatures in the range 25 to $200^{\circ} \mathrm{C}$ and are accounted for in terms of tre observed silicon precipitate and an associated dislocation structure. There was also a loss of ductility which was most severe at $200^{\circ} \mathrm{C}$. The fracture mode remained transgranular over the range of test temperatizes.

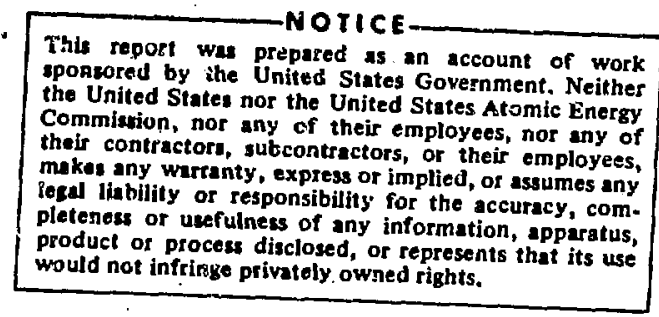

* Research sponsored by the U. S. Atomic Energy Commission under contract with the Union Carbide Corporation.

HOn attachment from Australian Atomic Energy Commission Research Establishment, Iucas Heights, N.S.W. 
INIRODUCTION

Aluminum sind its alloys are widely used in water-cooled research and test reactors because of their low cross section for absorption of thermal neutrons together with adequate strength and corrosion resistance. The 6061 alloy is interesting because it is a precipitation-hardened alloy in which high strengths can be attained by suitable manipulation of the $\mathrm{Mg}_{2} \mathrm{Si}$ precipitation reaction. Moreover, the alloy in its optimum age-hardened state is relatively ductile with over $17 \%$ total tensile elongation in the temperature range $-100^{\circ} \mathrm{C}$ to $+300^{\circ} \mathrm{C} .^{1}$

The effects of relatively low fluence neutron irradiation on the mechanical properties of this alloy have been investigated previously ${ }^{2-4}$ in the 0-temper (annealed), the T6 temper (optimum hardness), and in a cold worked condition. In general the 6061 aluminum en.joys an increase in strength but suffers a small loss in ductility when irradiaied and tested at temperatures below $150^{\circ} \mathrm{C}$. These observations suggest that high fiuences can be expected to induce significant strengthening and ductility joss, but the data are too meager to allow the extent of these changes to be forecast with confidence. Moreover, the microstructural changes responsible for the changes in mechanical properties have not been investigated. Accordingly, with a view to filling in these gaps, we have studied the mechanical properties and microstructure of an irradiated component from the High Flux Isotope Reactor (IIFIR), the 606.1 aluminum cylindrical target holder sleeve, exposed to high fast and thermal neutron fluences.

\section{FABRICATION AIND IRRADIATION HISTORY}

The fabrication procedure and irradiation history of the target sleeve and a more detailed description of the test data, including examination of 
a welded seam, are available in an ORNL report. ${ }^{5}$ Briefly the cylinder was made from $0.0625 \mathrm{in.}$ thick sheet of 6061 alloy of chemical composition $0.99 \mathrm{Mg}$, $0.65 \mathrm{si}, 0.45 \mathrm{Fe}, 0.22 \mathrm{Cr}, 0.21 \mathrm{Cu}, 0.06 \mathrm{Zn}, 0.06 \mathrm{Mn}, 0.05 \mathrm{Ti}, 0.02 \mathrm{Sn}$, $0.02 \mathrm{~Pb},<0.01 \mathrm{Ni}$ wt $\%$ obal $\mathrm{Al}$. This sheet was rolled to a $4.375 \mathrm{in}$. diam by 29.5 in. long cylinder and was seam welded with 4043 aluminum filler wire. The cylinder was then solution annealed at $520^{\circ} \mathrm{C}$, quenched to room temperature in circulating air and aged for $7 \mathrm{hr}$ at $190^{\circ} \mathrm{C}$. This treatment was designed to produce a condition close to the age-hardened T6 condition without incurring thermal distortion. After the cylinder was aged, holes werf drilled into it to allow free passage of cooling water during service. The sleeve was irradiated for a total of 65,715 MWd in the HFIR. This corresponds to a maximum fast-neutron finence of $9.2 \times 10^{22} \mathrm{n} / \mathrm{cm}^{2}(\mathrm{E}>0.1 \mathrm{MeV})$ and a thermal seutron fluence of $1.2 \times 10^{23} \mathrm{n} / \mathrm{cm}^{2}$ at the reactor midplane. ${ }^{6}$ The irradiation ternperature is estimated to have been $55^{\circ}$ to $65^{\circ} \mathrm{C}$.

\section{MEASUREMENT OF DENSITY CHANGES}

Density changes and tensile properties were measured on dogbone-shaped specimens shown in Fig. 1. This shape was determined by the perforations Il the cylinder. An oxide scale was formed on the exposed surfaces in the reactor cooling water and was about 0.0023 in. thick. It contained many cracks and pores. Density determinations were made by Archimedes displacement on specimens with the oxide film intact, and were repeated after the oxide was stripped from the specimens by chemical etching. The results of these measurements are summarized in Table 1 relative to the density of an unirradiated specimen, measured as $2.7012 \pm 0.0005 \mathrm{~g} / \mathrm{cm}^{3}$. The oxide is 
clearly less dense than the alloy and it contributes the larger portion of the overall density change measured on each specimen. The nature of the oxide is not known but $x$-ray powder diffraction patterns of oxide layers on some other HFIR aluminum components suggest ${ }^{7}$ that the oxide is $\beta-\mathrm{Al}(\mathrm{OH})_{3}$ (bayerite) and/or possibly $\propto-\mathrm{Al}(\mathrm{OH})_{3}$ (gibbsite) with theoreticaI densities of 2.53 and $2.42 \mathrm{~g} / \mathrm{cm}^{3}$, respectively. ${ }^{8}$

\section{MICROSTRUCTURAL EXAMINATION}

The microstructure of the unirradiated HFIK target holder sleeve is illustrated in Fig. 2. Iike most industrial aluminum alloys it had a large number of inclusions on grain boundaries and within the matrix. Regions adjacent to the grain boundaries were frequently denuded of the $\mathrm{Mg}_{\text {? }} \mathrm{Si}$ precipitate responsible for age hardening in the 6000 serjes aluminum alloys. The $\mathrm{Mg}_{2} \mathrm{Si}$ precipitate within the grains, shown more clearly in Fig. $2 b$, was in the form of both a coarse and a fine distribution of needles. Note the precipitate-free regions around the coarso $\mathrm{Mg}_{2} \mathrm{Si}$ needies. These large needles are not typical of a T6 temper and are probabiy a result of overaging or of slow cooling after the solution treatment.

After irradiation, voids (Fig. 3) were observed in specimens taken from the maximum flux region of the sleeve. None was seen on grain boundaries but they were clustered in regions parallel and close to the boundaries (Fig. 3a) and near large $\mathrm{Mg}_{2} \mathrm{Si}$ precipitates and large inclusions (Fig. 3b). This clustering of voids was confirmed by stereo microscopy and by the fact that there was a high incidence of clear cases of void coalescence within the clusters, a feature usually not observed in metals where the mean void 
concentration is only $2 \times 10^{14} / \mathrm{cm}^{3}$ as it was here. Comparison with the microstructure of the unirradiated material indicated that the voids were associated with those regions that were originally denuded of fine $\mathrm{Mg}_{2} \mathrm{Si}$ precipitate. The voids that are seemingly not clustered at large particles in Fig. 3 are probably those whose particles lay just outside the final foil thickness. No voids were found in specimens from the ends of the cylinder where the fast fluence was about $1.2 \times 10^{22} \mathrm{n} / \mathrm{sm}^{2}$. A few were observed, near large precipitates only, in specimens irradiated to $2.8 \times 10^{22}$ fast $\mathrm{n} / \mathrm{cm}^{2}$.

The precipitate structure in 6061 aluminum after neutron irradiation was more complex than that of the unirradiated ailoy. A high concentration of small precipitate particles is visible in Fig. 3o which was recorded under absorption contrast conditions so as to enhance the "visibility of voicis and make the $\mathrm{Mg}_{2} \mathrm{Si}$ precipitate invisible. We believe the precipitate seen in Fig. 3b is transmutation-produced silicon as identified in earlier studies of irradiated aluminum alloys. ${ }^{9}$ This silicon derives largely from a thermal neutron reaction, ${ }^{27} \mathrm{Al}(\mathrm{n}, \gamma)^{28} \mathrm{Al}$, fóllowed by a $\beta$-decay to ${ }^{28} \mathrm{Si}$. In specimens irradiated to $9.2 \times 10^{22} \mathrm{n} / \mathrm{cm}^{2}$ the average diameter of the silicon particles was approximately $170 \AA$ aid the concentration was about $1 \times 10^{16} / \mathrm{cm}^{3}$. The concentration of silicon particles appeared to be independent of fluence but the precipitate size increased with fluence in the range studied. This silicon precipitate is not to be confused with the fine coherent $\mathrm{Mg}_{2} \mathrm{Si}$ precipitate visible only under diffraction contrast coniditions.

The high strength of the unirradiated alloy is due to the coherent $\mathrm{Mg}_{2} \mathrm{Si}$ precipitate and thus it is important to know whether irradiation affected the stability of this precipitate. Unfortunately, the high density of 
the transmutation-produced silicon particles increased the extent of inage overlap and rendered contrast analyses extremely difsicult, Nevertheless, the large $\mathrm{Mg}_{2} \mathrm{Si}$ needles appeared to be unaltered by irradiation. Also, in very thin regions of the foils where image overlap was minimized, the characteristic streaking of $\mathrm{Mg}_{2} \mathrm{Si}$ precipitate reflections in selected area diffraction patterns appeared to be the same as that of the unirradiated alloy suggesting that no major irradiation-induced changes cocurred in the morphology of the coherent precipitate. Problems of image overlap in diffraction contrast also interfered with attempts to study closely the dislocation structure in the irradiated alloy. These dislocations (Fig. 4) were irregular secments which nay be parts of loops larger than the foil thickness, formed by the agglomeration of point defects created during irradiation. A summary of quantitative measurements of the "irradiationinduced defects is presented in Table 2.

\section{MECHANICAL PROPERTY MEASUREMEITS}

Tensile tests were made in air in an Instron testing machine using special grips to accommodate the specimen shape. For all practical purposes, the test specimen may be considered as a sheet tensile specimen with zero gage length and hence strain, strain rate and stress state carnot be defined. Nevertheless, the curves for applied load versus the Instron crosshead displacement (Fig. 5) were of similar form to those normaliy obtained from standard tensile specimens. Engineering stress values were computed from the pertinent load values and the measured original cross-sectional areas of the individual specimens. The cross-sectional area included the oxide film which fractured readily at low strains during testing and probably did not bear any load at the ultimate load point. 
The yield stress was arbitrarily defined at a crosshead offset from the apparent elastic region of 0.00002 in. The magnitudes of the crosshead. displacement between the yield point and the maximum load, and between the yield point and the point of fracture, were arbitrarily chosen as measures of the uiliform and total plastic extensions, respectively, as illustrated in Fig. 5. These, data should not be used for engineering design purposes, but they are believed to provide an internally consistent comparison of our irradiated and unirradiated specimens. Because of the reactor-oriented nature of this investigation, the tests were performed at temperatures ranging between room temperature and $200^{\circ} \mathrm{C}$, the anticipated maximum range of operating temperatures for this alloy in the HF'IR. A pericd of $20 \mathrm{~min}$ was allowed to heat the specimens to the tèst temperature. Strain rate effects were measured by changing the Instron crosshead speed.

The effects of neutron fluence and test temperature at several crosshead speeds on the yield stress and the ultimate stress are shown for the higher fIuence specimens in Fig. 6. There are significant radiationinduced increases in strength, particularly at the lower test temperatures. The ductility of the specimens is shown in FiE. 7. Under all conditions of fluence, test temperature and crosshead speed the plastic extension to the ultimate stress was a little larger in the unirradiated specimens than in the irradiated ones. Irradiation caused a much greater reduction in the total plastic extension, particularly at the higher test temperatures and the slowest crosshead speed. 


\section{EXAMINATION OF FRACTURED SPECIMENS}

Specimens tested at the lowest strain rates were examined to determine the mode of fracture. The unirradiated specimens showed more evidence of necking near the fracture surfaces but scanning electron microscopy of the actual fractures revealed only dimnled surfaces, characteristic of ductile, transgranular tearing and shearing. We could not obtain useful transmission electron microscopy specimens from regions near the fractures to see if deformation had changed the microstructure, but specimens taken from regions away from the fractures showed that the short times that the specimens spent at the test Eemperatures did not modify the microstructures. Indeed, annealing experiments re have made on irradiated specimens confirm that the voids and the $\mathrm{Mg}_{2} \mathrm{Si}$ recipitate are stable during a l-br anneal at $200^{\circ} \mathrm{C}$. The voids disappear it $350^{\circ} \mathrm{C}$.

\section{DISCUSSION}

The observed swelling of the 6061 aluminum from the HFIR target basket an be separated into three contributions, one from the oxide films, one from adiation-induced voids and the third from the transrautation-produced silicon resipitate. Table 1 shows that the oxide filin formed in contact with the eactor coolant constituted the major part of the overall swelling. Moreover, his contribution increased with neutron fluence, or neutron flux since all pecimens were taken from the one sleeve. The reason for this correlation is ot known.

The swelling measured on specimens from which the oxide was removed was aused by roids and transmutation-produced silicon precipitate. Swelling due to jids alone was measured on several specimens by quantitative electron microcopy", with the results shown in Table 3. The difference between these velues ad the measured density changes on the oxide-stripped specimens should 
then be the contribution from the silicon precipitate. Alternatively, we can determine the contribution from silicon by estimating the amolint of transmutation-produced silicon. The spectrum averaged cross-section for the silicon reaction is 0.179 barns for neutron energies below $0.414 \mathrm{eV}^{1.0}$ Specimens in the reactor midplane position received $1.2 \times 10^{23} \mathrm{n} / \mathrm{cm}^{2}$ (thermal), corresponding to 2.1 wt $\%$ Si. At the irradiation temperature $\left(60^{\circ} \mathrm{C}\right)$ silicon is virtually insoluble and we assume that all of the transrutation-produced silicon is precipitated. The rule of mixtures can then be used to calculate the swelling from silicor, usirg a density of $2.3293 \mathrm{~g} / \mathrm{cm}^{3}$ for the silicon particles ${ }^{8}$ and $2.7012 \mathrm{~g} / \mathrm{cm}^{3}$ for the 6061 aluminum. On this basis, each $I$ wt $\% \mathrm{Si}$ in the form of precipitate causes the 6061 a?uminum to swell by $0.16 \%$. In colum 4 in Table 3 we have listed the estimated swelling values from silicon in tho se specimens on which the swelling contribution from voids was measured. If the contributions from voias and silicon are summed (column 5) there is good agreenent with the measured immersion density changes in the oxidestripped alloy. Table 3 also shows that swelling from silicon exceeds that from voids at fluences below $6 \times 10^{22} \mathrm{n} / \mathrm{cm}^{2}$ (fast), but that as the fluence is increased the swelling from voids increases at a faster rate than that from silicon.

The overall swelling in the 6061 aluminum, excluding that from the oxide layer, is very much smaller than has been found in any other aluminum alloy subjected to high, fast neutron fluences. ${ }^{11}$ For example, a fast neutron fluence of $\sim 3 \times 10^{22} \mathrm{n} / \mathrm{cm}^{2}$ gires $1 \%$ swelling in annealed 1100 grade aluminum and about $2.5 \%$ swelling in cold-draw 8001 aluminum. A fluence of $1.6 \times 10^{22} \mathrm{n} / \mathrm{cm}^{2}$ causes $7.5^{\circ}$ swelling in high purity aluminum. 12 
Silicon is generated in all of these materials but the major diflerences in swelling arise from differences in the total volume of voids. The one feature present in the irradiated 6061 aluminum and absent in the other irradiated materials is the coherent $\mathrm{Mg}_{2} \mathrm{Si}$ precipitate, and we believe that the 6061 aluminum owes its superior resistance to void. formation to the presence of this precipitate. The observation that voigs occurred only in those regions free or the precipitate support this view and lead to the tentative conclusion that if the aged 6061 aluminum sleeve had been in a proper T6 cordition with a uniformly distributeù fine $\mathrm{Mg}_{2} \mathrm{Si}$ precipitate there would probably have been much less swelling contribution from voids. However, the $\mathrm{Mg}_{2} \mathrm{Si}$ precipitate would not alleviate swelling from the transmatation-produced silicon.

This effect of the $\mathrm{Mg}_{2} \mathrm{Si}$ precipitate is in qualitative agreement with a recent ${ }^{13}$ observation that swelling is resisted in irradiated Nimonic PEl6 alloy when a high concentration of coherent $y^{\prime}$ precipitate particles are present. The mechanism by which coherent particles prevent void formation is not clear. Bullough, and Perrin ${ }^{14}$ have suggested that the coherent interface may trap displaced atoms and vacancies during irradiation and thus promote recombination. On the other hand, the high dislocation density stabilized by coherent precipitate particles cay promote recombination by one of the mechanisms proposed by Bullough and Perrin ${ }^{12}$ and by Harkness and $I_{i .}{ }^{15}$ There is evidence, 16 too, that the transmutation-produced gases, helium and hydrogen, enhance void nucleation, and if these gases are trapped by precipitates their effectiveness as void nuclei mig!t be diminished.

The radiation-induced increases in yield and ultimate stresses can be a.tributea primarily to the transmutation-produced silicon precipitate 
and to the increase in dislocation density during irradiation. There was no observable change in the $\mathrm{Mg}_{2} \mathrm{Si}$ precipitate that might have influenced the strength. The gases generated from $(n, \alpha)$ and $(n, p)$ reactions, sstimated at 40 at. ppn helium (we measured 41 at. ppm) and 230 at. ppm hydrogen, did not form visible butbles. Ii slich gases were present as submicroscopic bubbles, < $20 \AA$ diam, their hardening contribution would be negligible, according to Kroupa and Hirsch. ${ }^{17}$

The increase in yield stress from silicon particles alone can ve calculate ${ }^{2}$ using Askby's ${ }^{18}$ modification of the Orowen model of strengthening by hard particles:

$$
\Delta \sigma_{\mathrm{Si}}=\frac{1.13 \mathrm{~Gb}}{\pi l} \ln \left(\frac{\mathrm{d}}{\mathrm{r}_{0}}\right), \quad \therefore .
$$

where the shear modulus $G=2.7 \times 10^{3} \mathrm{~kg} / \mathrm{mm}^{2}$ at room temperature, the Burgers vector $\mathrm{b}=2.86 \times 10^{-3} \mathrm{~cm}$, $\mathrm{d}$ is the mean particle diameter, the dislocation cut-off radius $r_{0}$ is usually assumed equal to $4 \mathrm{~b}$ or $\sim 1 \times 10^{-7} \mathrm{~cm}$, and $\ell$ is the nean planar particle separation, given ${ }^{19}$ by

$$
\ell=\frac{a}{4}\left(\frac{2 \pi}{3 f}\right)^{1 / 2}
$$

where $f$ is the volume fractior of precipitates. For a specimen irradiated to $9.2 \times 10^{22} \mathrm{n} / \mathrm{cm}^{2}(0.1 \mathrm{MeV})$ and $1.2 \times 10^{23} \mathrm{n} / \mathrm{cm}^{2}(<0.414 \mathrm{eV})$, the silicon particle density was determined by electron microscopy to be $10^{16} / \mathrm{cm}^{3}, f=0.025$ and $\mathrm{d}=1.7 \times 10^{-6} \mathrm{~cm}$. Consequently, $\ell=3.9 \times 10^{-6} \mathrm{~cm}$ and from Eq. (1), $\Delta 0_{\mathrm{Si}}=29,200 \mathrm{psi}$. The yield stress increase from dislocations alone follows the relation 20

$$
\Delta \sigma_{d}=\alpha G b(\Lambda)^{1 / 2}
$$


where $\alpha$ is about 1.0 and $\Lambda$ is the dislocation density. For $\Lambda=2.5 \times 10^{10} / \mathrm{cm}^{2}$, $\Delta \sigma_{\mathrm{d}}$ is $17,400 \mathrm{psi}$. Voids also . ontribute to hardening ${ }^{21}$

$$
\Delta \sigma_{\mathrm{v}}=2 \mathrm{~Gb} / \mathrm{L}
$$

where $I=(N d)^{-1 / 2}$. Consequently, for $\mathbb{N}=1.92 \times 10^{14} / \mathrm{cm}^{3}$ and $d=3.5 \times 10^{-6} \mathrm{~cm}$, $\Delta \sigma_{\mathrm{v}}=5,800 \mathrm{psi}$.

These various contributions to the yiald stress are not simpiy additive. The combined effect is given by the square root of the sum of the squares of the individual contributions. 22 We do this as follows: Prior to irradiation, the 6061 aluminum contained a high concentration of $\mathrm{Mg}_{2} \mathrm{Si}$ particles and a dislocation density of $2 \times 10^{9} / \mathrm{cm}^{2}$, and it had a yield stress at room temperature of about 30,000 psi. Annealed 1100 grade aluminum, which is presumably the base material for the manufacture of the alloy, contains neither the $\mathrm{Mg}_{2} \mathrm{Si}$ precipitate nor the dislocations and has a yield stress, $\dot{\sigma}_{0}$, of 5,000 psi. 1 Hence we consider that 6061 aluminum prior to irradiation contains obstacles responsible for a yield stress increment of 25,000 psi. This increment we call $\Delta \sigma\left(\mathrm{Mg}_{2} \mathrm{Si}+\mathrm{d}\right)^{\cdot}$ Thus the yield stress of the unirradiated alloy is given by

$$
\sigma_{u}=\sigma_{0}+\Delta \sigma\left(\mathrm{Mg}_{2} \mathrm{Si}+\mathrm{d}\right)
$$

and that for the irradiated material is

$$
\left.\sigma_{i r r}=\sigma_{0}+\left[\Delta \sigma_{\left(M g_{2} S i\right.}^{2}+d\right)+\Delta \sigma_{S i}^{2}+\Delta \sigma_{d}^{2}+\Delta \sigma_{v}^{2}\right]^{I / 2}
$$

Predicted values of room temperature yield stress derived from Eq. (6) using our microstructural measurements are listed in Table 2 as functions of neutron fluence and are in good agreement with the observed values. At 
fluences above 2 to $4 \times 10^{22} \mathrm{n} / \mathrm{cm}^{2}$ the concentrations of dislocations and silicon particles appeared to be saturated; the increasing strength of the alloy becomes dependent only on the increasing size of the silicon particles and thus is less sensitive to neutron fluence than it is at lower fluences where the concentration of defects is below saturation.

The loss in mechanical strength with increasing test temperature is common to irradiated and unirradiated specimens and is caused largely by the normal decrease in the elastic modulus of the aluminum matrix. The loss is greater in the irradiated alloy but we could not detect any microstructural changes that could account for this.

The observed ductility changes are nct easy to explain. The major difficulty is that the test specimens had no built-in gauge length. Consequentiy, during testing, as the narrowest region of the specimen work hardened, the plastically strajned region no doubt spread back from the neck into the wider parts of the specimen, thus continuously increasing the effective gauge length. Moreover, the extent of this effect may have changed with test temperature and strain rate. Despite these ccnsiderations, however, the general trends of the ductility changes are not unusual for a materiai irradiated at this low temperature. The interesting and the most important observation is that whereas the total plastic extension increased with increasing test temperature in the unirradiated specimens, it was reduced by irradiation and decreased with increasing test temperature, particularly at the slowest crosshead speed. Elevated temperature, irradiation-induced ductility loss is often caused by helium embrittlement 23,24 and is usually associated with intergranular fracture. Such intergranular fracture is most prevalent under slow strain rate conditions. The 6061 aluminum dogbone specimens, both irradiated and unirradiated, failed by ductilc tearing under all conditions of testing. 
Ductile dimple formation leading to fracture is characteristic of a rapid strain rate process where high local strains open up holes at obstacles such as inclusions. There were many such obstacles in the dogbone 6061 aluminum specimens, most of them surrounded by zones free of $\mathrm{Mg}_{2} \mathrm{Si}$ precipitate. Despite the apparently slow crosshead speeds at which some of these specimens were tested, the actual strain rates were very high because the specimens had essentially no gauge length. The irradiated specimens tested at the lowest crosshead speed of $0.0002 \mathrm{in.} / \mathrm{min}$ at $200^{\circ} \mathrm{C}$ lasted only about 15 min before fracture. Irradiated and unirradiated specimens tested at the highest crosshead speed lasted less than 1 min. Even the longest test in the unirradiated specimens took only $4 \mathrm{hr}$. These are fast tests in relation to the creep-type tésts under which intergranular fracture is predominant. We picture the fracture process in the dogbone specimens as one involving tearing or dimple fornation in the $\mathrm{Mg}_{2} \mathrm{Si}$ precipitate-free zones around inclusions and the large $\mathrm{Mg}_{2} \mathrm{Si}$ rods in both the irradiated and the unirradiated specimens. Irradiation modifies the fracture process to the extent that it hardens the matrix and the regions around inclusions and large $\mathrm{Mg}_{2} \mathrm{Si}$ particles, and introduces clusters of voids around the particles. During testing these voids may serve as pre-existing ductile dimple embryos and/or the hardened regions around the inclisions may tear at lower strains than in the unirradiated material. Consequently, the plastic extension to the ultimate stress will be lowered and the general ductility to fracture will also be reduced. In this view, the same fracture sites are involved in both cases and, indeed, we could see no differences in the fracture. surfaces of irradiated and unirradiated specimens. The particularly poor ductility of the irradiated specimens at $200^{\circ} \mathrm{C}$ and the lowest crosshead speed is not understood. It is 
worth mentioning though, that in testing a number of irradiated aluminum alloys we have in all cases found a significant ductility loss at $200^{\circ} \mathrm{C}$.

\section{CONCLUSIONS}

Age-hardened 6061 aluminum shows the best resistance to void formation of any irradiated aluminum alloy studied to date. Voids are not detected at fluences below $2.8 \times 10^{22} \mathrm{n} / \mathrm{cm}^{2}(0.1 \mathrm{MeV}$ ) and account for about $0.7 \%$ swelling after exposure to $\left.9.2 \times 10^{22} \mathrm{n} / \mathrm{cm}^{2} \rightarrow 0.1 \mathrm{MeV}\right)$. Additional swelling arises from the formation of a precipitate of transmutation-producea silicon and from the growth of a surface oxide film. The disposition of the voids in the microstructure suggests that swelling from voids may be minimized by assuring that the 6061. aluninum contains a uniformidistribution of fine, coherent $\mathrm{Mg}_{2} \mathrm{Si}$ precipitates before irradiation.

Radiation-induced strengthening in precipitation-hardened 6061 aluminum is caused by the transmutation-produced silicon. precipitate, and increased dislocation density and voids. Irradiation also reduces the ductility of the alloy, the loss being most severe at a test temperature of $200^{\circ} \mathrm{C}$ and a nominally slow testing speed. The fracture process remained transgranular and was characterized by dimpled fracture surfaces typical of ductile failure.

\section{: ACKNOWLEDGEMENT}

We wish to thank R. A. Iines of the Hot Cells Operations for preparing the specimens, E. Bolling for the mechanical properties testing, L. D. Hulett for collaborating on the scanning electron microscopy work, and J. T. Houston for preparing the electron microscopy specimens. The comments and adrice of J. R. Weir, E. L. Long, Jr., E. E. Bloom, and J. O. Stiegler during the course of this work are gratefull.y appreciated. 


\section{REFERENCES}

1. Alcoa Aluminum Handbook, Aluminum Company of America, Pittsburgh, Pennsylvania, 1967.

2. McCoy, H. E. and Weir, J. R., Jr., "Influence of Irradiation on the Tensile Properties of the Aluminum Alloy 6061," Nucl. Sci. and Engr., Vol. 25,1966, pp. $319-327$.

3. Steele, R. V. and Wallace, W.P., Effect of Neutron Flux on the Mechanical Properties of Aluminum Alloys, LRL-145 (1954).

4. Gronbeck, H. D., ETR Radiation Damage Surveillance Programs Progress Report II, IN-1036 (1967).

5. King, R.T., Jostsons, A. and Farrell, K., "Examination of the Irradiated 6061 Aluminum HFIR Target Holder Sleeve," USAEC Report ORIL-TM, to be published, Oak Ridge National Laboratory, Oak Ridge, Tennessee.

6. Kam, F.B.K. and Swanks, J. H., Neutron Flux Spectrum in the HFIR Target Region, USAEC Report ORNL-TM-3322, Oak Ridge, National Labcratory, Oak Ridge, Tennessee, 1971.

7. Tennery, V.J., Oak Ridge National Laboratory, private communication.

8. Handbook of Chemistry and Physics, 52nd ed., R. C. Weast, editor, Chemical Rubber Publishing Co., Cleveland, Ohio, 1971.

9. Farrell, K., Stiegler; J.0. and Gehlbach, R., "Transmutation--Produced Silicon Precipitates in Irradiated Aluminum," Nietallography, Vol. 3, 1970, pp. 275-284.

10. Jenkins, J.D., , Oak Ridge National Laboratory, private communication.

11. Jostsons, A., Iong, E.L., Jr., Ferguson, J.E. and Farrell, K., "Swelling In Aluminum and Its Alloys," presented at the 1971 Fall Meeting of Met. Soc. ATME, Detroit, Michigan, October 1971, to be published. 
12. Packan, N.H., "Fluence and Flux Dependence of Void Formation in Pure Aluminum," J. Nucl. Mater., Vol. 40, 1971, pp. 1-16.

13. Bramman, J.I., Bagley, K.G., Cawthorne, C., FuIton, E.J. and Sinclair, W.D.J., "Density Changes in Cladding Materials Irradiated in DRF," Proceedings of British Nuclear Energy Society European Conference on Voids Formed by Irradiation of Reactor Materials, Reading, March 1971, p. 27.

14. Bullough, R. and Perrin, R.C., "Theory of Void Formation and Growth in Irradiated Materials," presented at the International Conference on Radiation-Induced Voids in Metals, Albany, New York, June 1971, to be published.

15. Harkness, S.D. and Che-Yu Ii, "A Theoretical Study of the Swelling of Fast-Neutron Irradiated Máterials," ibid.

16. Farrell, K., Wolfenden, A. and King, R.T., "The Effects of Irradiation Temperature and Pre-Injected Gases on Voids in Aluminum," Radiation Effects, Vol. 8, 1971, pp. 107-114.

17. Kroupa, F. and Hirsch, P. B., "HIastic Interaction Between Prismatic Dislocation Ioops and Straight Dislocations," Discussions of the Faraday Society, No. 38, 1964, pp. 49-55.

18. Ashby, M. F., "On the Orowan Stress," in Physics of Strength and Plasticity, ed. by A. S. Argon, the MIT Press, Cambridge, Massachusetts, 1969, pp. 113-3i.

19. Martin, J. W., Precipitation Hardening, Pergamon Press, 1968, p. 215.

20. McLean, D., Mechanical Properties of Metals, John Wiley and Sons, 1962, p. 149 .

21. Coulomb, P., "Sur le Blocage des Dislocations par des Cavities ou de Petits Precipites," Acta Met., Vol. 7, 1959, p. 556. 
22. Kocks, U. F., "A Statistical Theory of Alloy Harảening," in Physics of Strength and Plasticity, ed. by A. S. Argon, the MIT Press, Cambridge, Massachusetts, 1969, p. 143.

23. Barnes, R. S., "Embrittlement of Stainiess Steels and Nickel-Based Alloys at High Temperature Induced by Neutron Irradiation, "Nature, Vol. 206, 1965, p. 1307.

24. Stiegler, J. O. and Heir, J. R., Jr., "Effects of Irradiation on Ductility," in Ductility, Proceedings of ASM Seminar, October 1967, p. 311. 
Table 1. Density Changes with and without the Oxide Film

\begin{tabular}{ccc}
\hline $\begin{array}{c}\text { Fast (E }>0.1 \mathrm{MeV}) \\
\text { Neutron Fluence } \\
\left(x 10^{22} \mathrm{n} / \mathrm{cm}^{2}\right)\end{array}$ & $\begin{array}{c}\text { Density Change, } \% \\
\text { With } \\
\text { Oxide }\end{array}$ & $\begin{array}{c}\text { Without } \\
\text { Oxideb }\end{array}$ \\
\hline 1.2 & -0.99 & -0.02 \\
2.8 & -0.99 & -0.14 \\
4.5 & -1.13 & -0.18 \\
6.0 & -1.61 & -0.60 \\
7.3 & -1.92 & -0.76 \\
8.3 & -2.22 & -0.92 \\
8.9 & -2.36 & - \\
9.2 & -2.53 & -1.06 \\
\hline Precision of $\pm 0.3 \%$. & &
\end{tabular}


Table 2. Quantitative Metallogrephy of Irradiation-Induced Defects in 6061 Specimens,

and a Comparison of Celculated and Observed Yield Stresses at Room Temperature

\begin{tabular}{|c|c|c|c|c|c|c|c|c|}
\hline $\begin{array}{r}\text { Neutron } \\
\left(\times 10^{22}\right. \\
\end{array}$ & $\begin{array}{l}\text { Fluence } \\
\left.\mathrm{n} / \mathrm{cm}^{2}\right)\end{array}$ & \multirow{2}{*}{$\begin{array}{c}\text { Concentration } \\
\text { of Voids } \\
\left(\times 10^{14} / \mathrm{cm}^{3}\right)\end{array}$} & \multirow{2}{*}{$\begin{array}{c}\text { Mean } \\
\text { Void } \\
\text { Diameter } \\
\left({ }^{\circ} \mathrm{A}\right)\end{array}$} & \multirow{2}{*}{$\begin{array}{l}\text { Concentration } \\
\text { of Silicon } \\
\text { Perticles } \\
\left(\times 10^{16} / \mathrm{cm}^{3}\right)\end{array}$} & \multirow{2}{*}{$\begin{array}{c}\text { Mean } \\
\text { Silicon } \\
\text { Particle } \\
\left.\text { Size ( }{ }^{\circ} \mathrm{A}\right)\end{array}$} & \multirow{2}{*}{$\begin{array}{c}\text { Dislocation } \\
\text { Density } \\
\left(\times 10^{20}\right. \\
\left.\text { lines } / \mathrm{cm}^{2}\right)\end{array}$} & \multirow{2}{*}{$\begin{array}{c}\text { Calculated } \\
\text { Yield } \\
\text { Stress } \\
\text { (x } 1000 \text { psi })\end{array}$} & \multirow{2}{*}{$\begin{array}{c}\text { Measured } \\
\text { Yield } \\
\text { Stress } \\
(\times 1000 \text { psi) }\end{array}$} \\
\hline$>0.1 \mathrm{MeV}$ & $<0.414 \mathrm{eV}$ & & & & & & & \\
\hline 0 & 0 & 0 & 0 & 0 & 0 & 0.2 & --- & 30.0 \\
\hline 1.2 & 1.5 & $\ldots$ & $-\infty$ & $-\infty$ & -- & --- & --- & 37.0 \\
\hline 2.8 & 3.6 & 0.1 & 200 & $\sim 1$ & 85 & 2.3 & 44.0 & 43.0 \\
\hline 4.5 & 5.7 & $-\infty$ & --- & $-\infty$ & $-\infty$ & $-\infty$ & --- & 46.0 \\
\hline 6.0 & 7.6 & 1.4 & 310 & $\sim 1$ & 145 & 2.7 & 44.9 & 48.0 \\
\hline 7.3 & 9.3 & $-\infty$ & $-\infty$ & $-\infty$ & -- & -- & -..- & 49.0 \\
\hline 8.3 & 10.5 & $\cdots$ & $-\cdots$ & $-\cdots$ & $-\infty$ & $\ldots$ & -..- & 49.0 \\
\hline 9.2 & 11.6 & 1.9 & 370 & $\sim 1$ & $1 \% 0$ & 2 to 3 & 48.0 & $5 . .0$ \\
\hline
\end{tabular}

* Yeasured yield stresses are taken from a smooth-line fit of the b.oader experimental data, given in ref. 5 . 
Table 3. Swelling from Voids and Silicon Precipitate in Irradiated 6061 Alloy

\begin{tabular}{|c|c|c|c|c|c|}
\hline \multicolumn{2}{|c|}{ Neutron Fluence $\left(\times 10^{22} \mathrm{n} / \mathrm{cm}^{2}\right)$} & $\begin{array}{l}\text { Measured } \\
\text { Swelling from } \\
\text { Voids }(\%)\end{array}$ & $\begin{array}{l}\text { Estimated } \\
\text { Swelling from } \\
\text { Silicon } \\
\text { Precipitate }(\%)\end{array}$ & $\begin{array}{l}\text { Swelling } \\
\text { from Voids } \\
\text { and Silicon }(\%)\end{array}$ & $\begin{array}{c}\text { Measured } \\
\text { Density } \\
\text { Decrease }(\%)\end{array}$ \\
\hline 2.8 & 3.6 & $<0.01$ & 0.17 & $\sim 0.18$ & 0.18 \\
\hline $6.0^{\circ}$ & 7.6 & 0.24 & 0.23 & 0.47 & 0.60 \\
\hline 9.2 & .11 .6 & 0.68 & 0.35 & 1.03 & 2.06 \\
\hline
\end{tabular}


ORNL-OWG $72-3037$
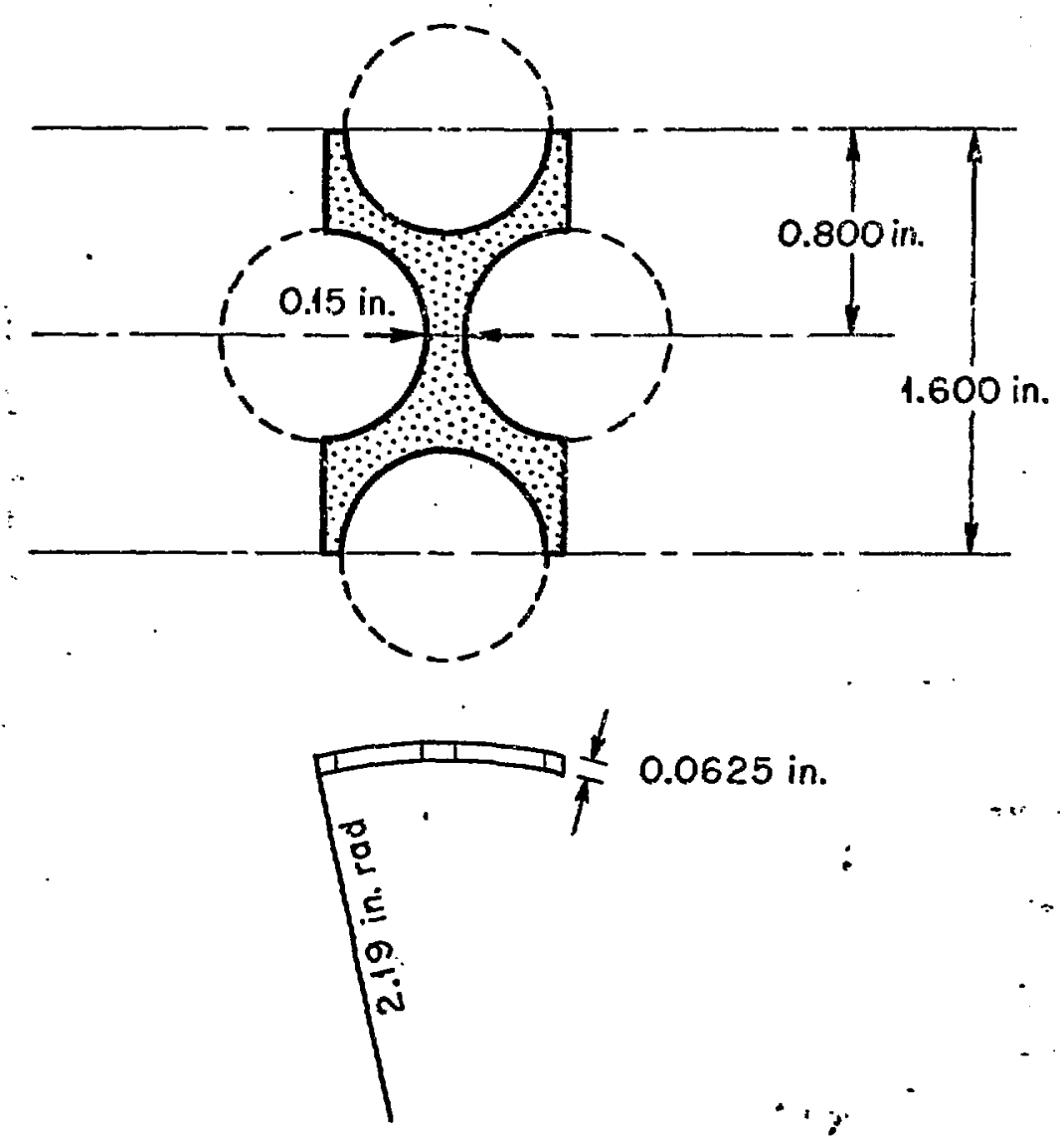

Dimenticins

Fig. 1. feometry of the dogbone-shaped tensile specimen. 

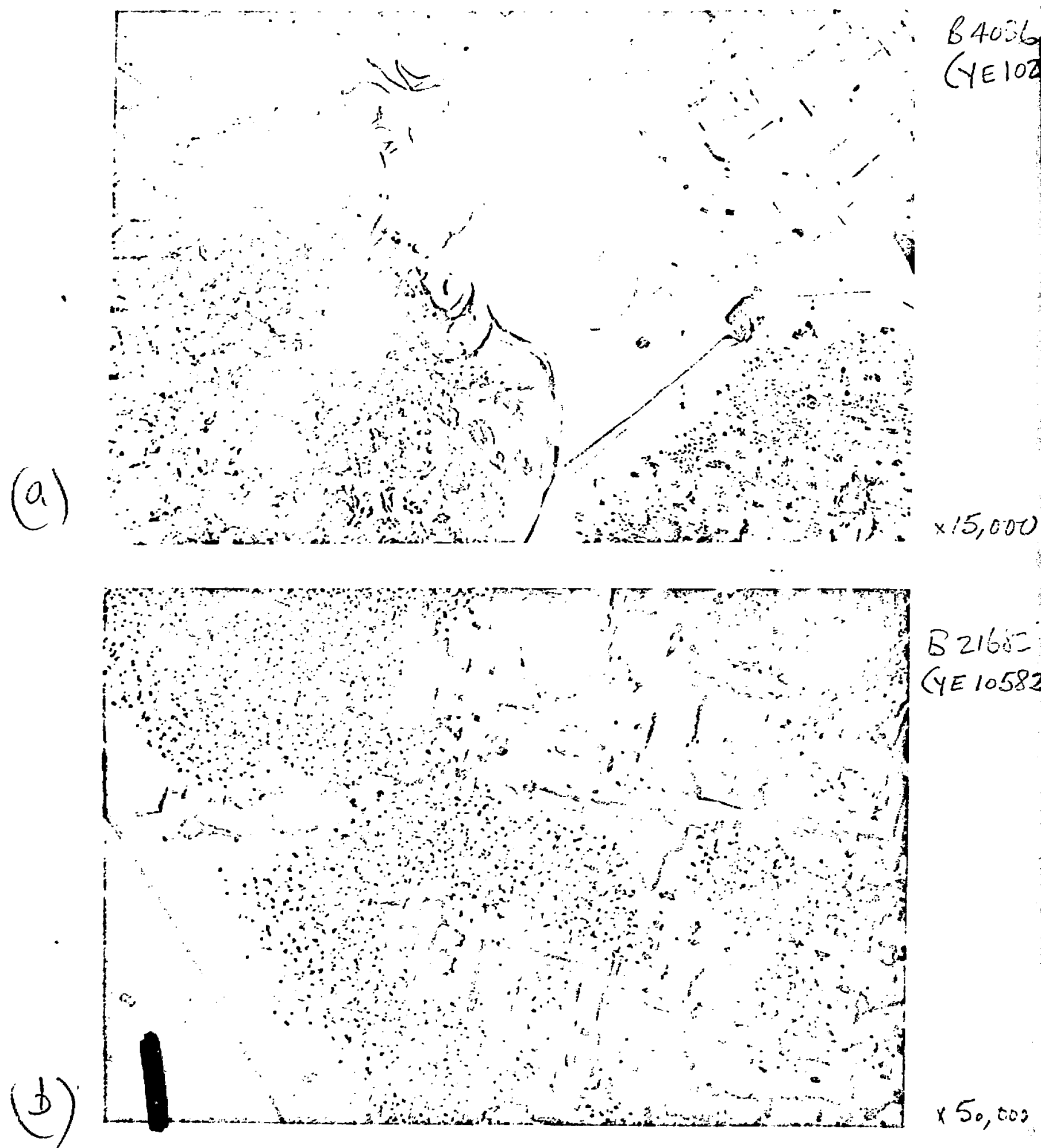

Fig. 2. Microstructure of 6061 aluminum from an unirradiated FFIR target bagiet. (a) Large inclusions near grain boundaries which are denuded of the fine'coherent Mgesi precipitate. Regions of the matrix imaged in absorption contrast reveal only large $\mathrm{M}_{3} \mathrm{Si}$ roàs (airowed) and do not show the fine coherent $\mathrm{Mg}_{2} \mathrm{Si}$ precipitate. (b) At higher magnification, denudi: of the fine coherent $\mathrm{Mg}_{2} \mathrm{Si}$ precipitate is clearly demonstrated around some of the large $/ \mathrm{g}_{2} \mathrm{Si}$ rods as well as near the grain boundary. 


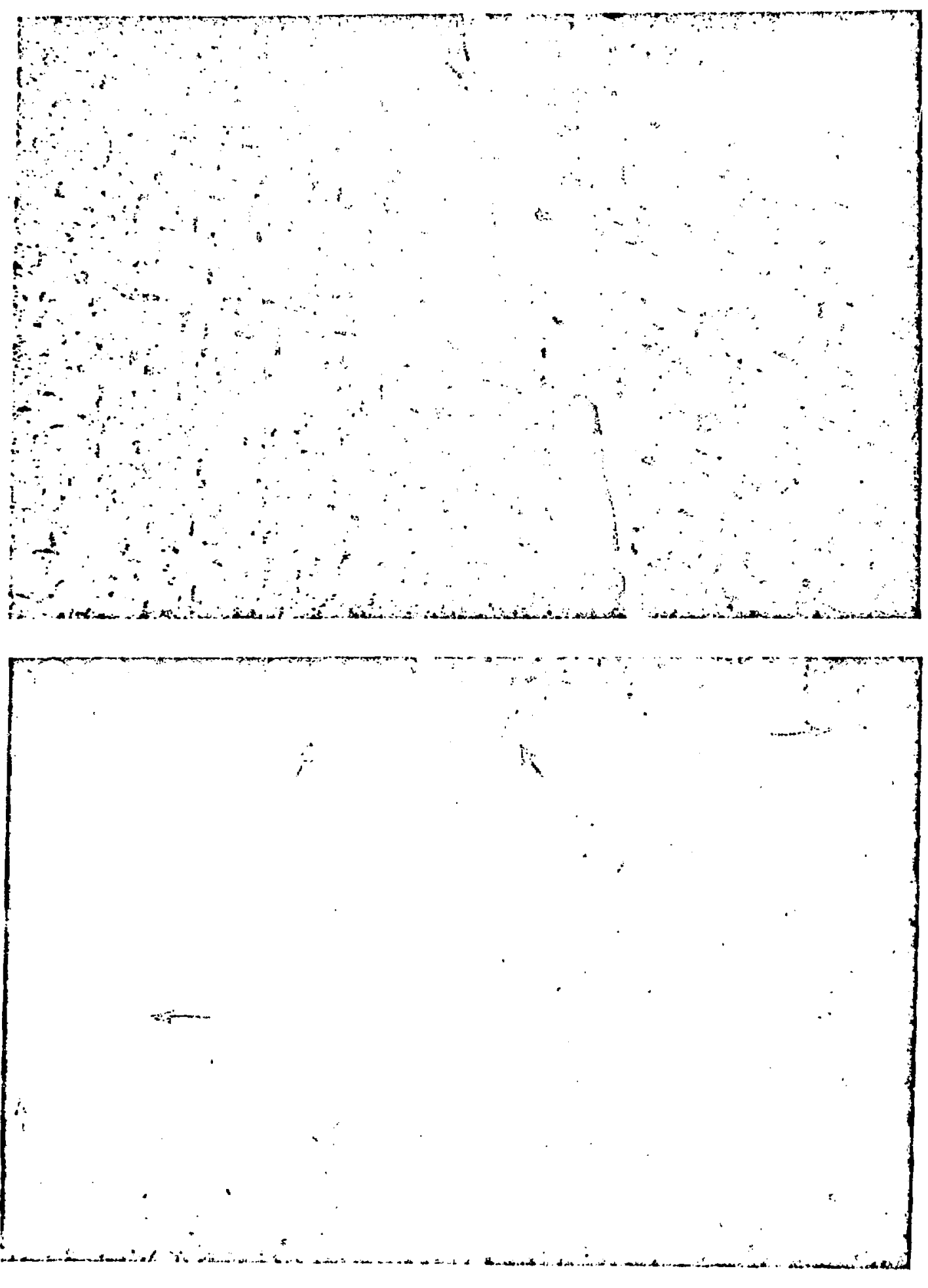

Fig. 3. Microstructure of 6061 ajuminum irradiated at $60^{\circ} \mathrm{C}$ to fluences of $9.2 \times 10^{22} \mathrm{n} / \mathrm{cm}^{2} \rightarrow 0.1 \mathrm{MeV}$ ) and $1.2 \times 10^{23} \mathrm{n} / \mathrm{cm}^{3}$ (thermal). (a) Clustering of voids near grain boundaries and near large $M_{E}{ }_{2} S i$ rod-like precipitate particles. (b) At higher magnification the clustering of voids near the large $\mathrm{Mg}_{2} \mathrm{Si}$ rods is more obvious and instances of voids having undergone coalescence are arrowed. The fine background precipitate is transmutationproduced silicon. Both (aj) and (b) rerc recorded under absorption contrest. 


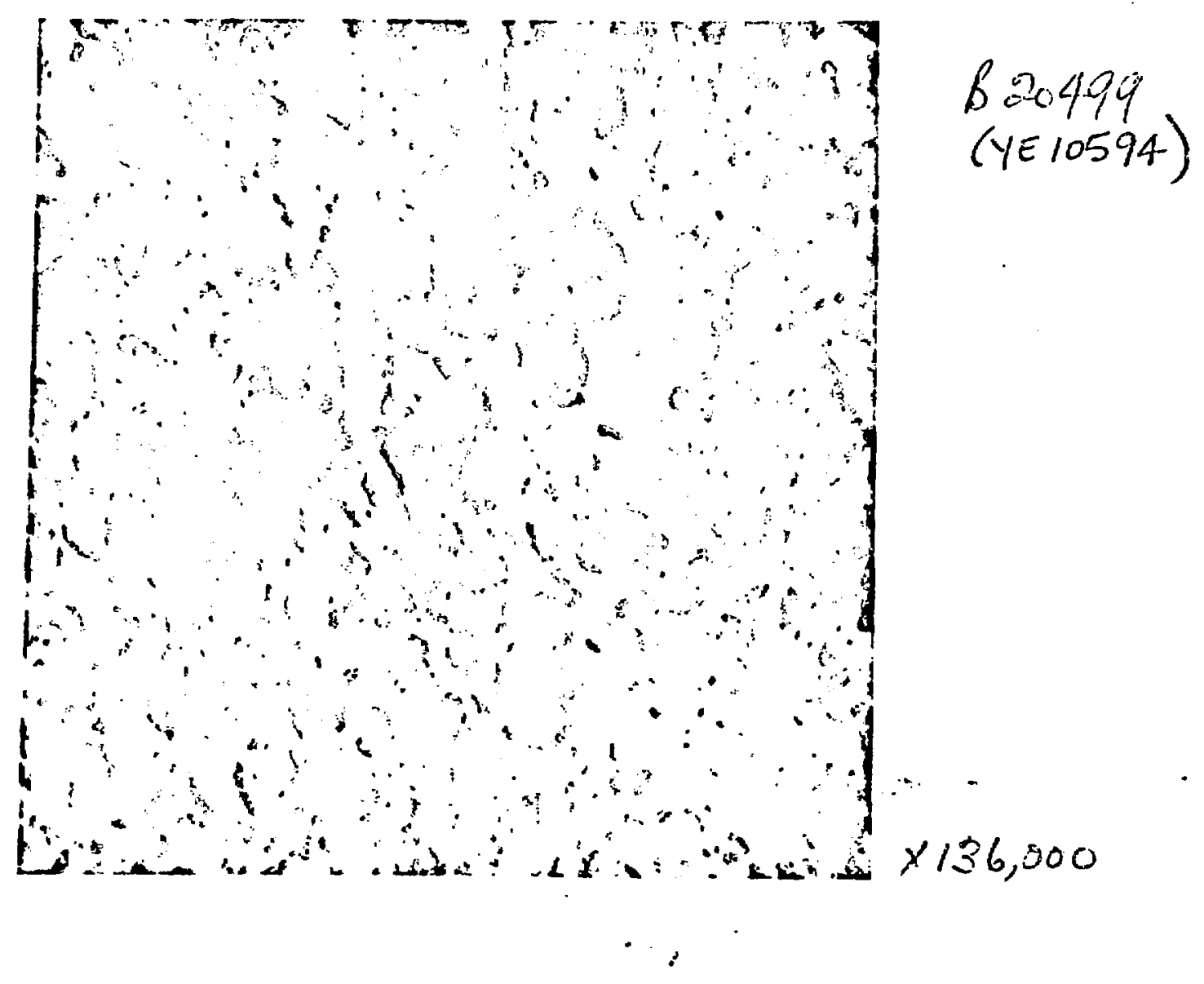

Fig. 4. Microstucture of irradiated 6061 aluminum recorded using diffraction contrast to reveal the dislocation structure and a high concentration of fine precipitate particles. 


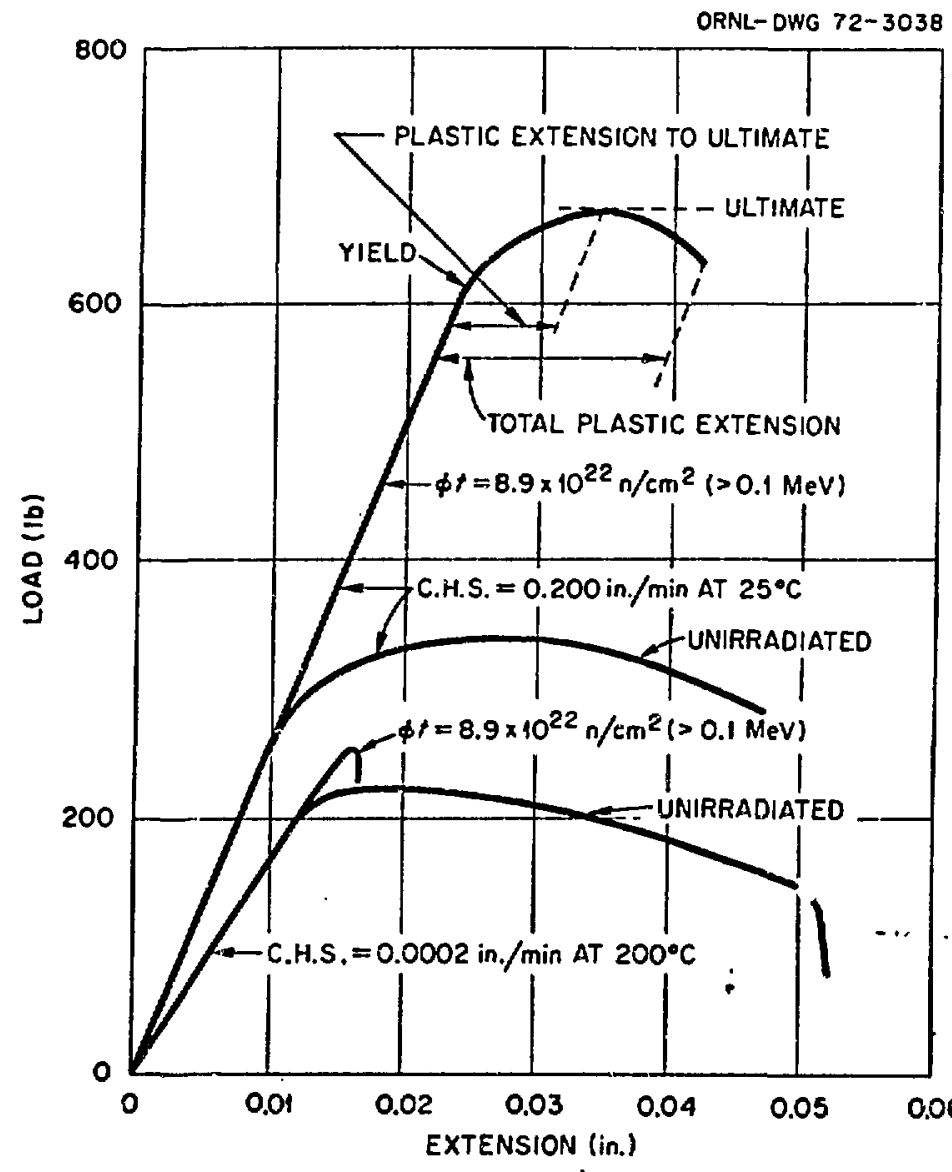

Fig. 5. Typical load-extension curves obtained from the dogbone Instivin specimens. The stress and strain parameters are indicated. C.H.S. is the cressherd, 


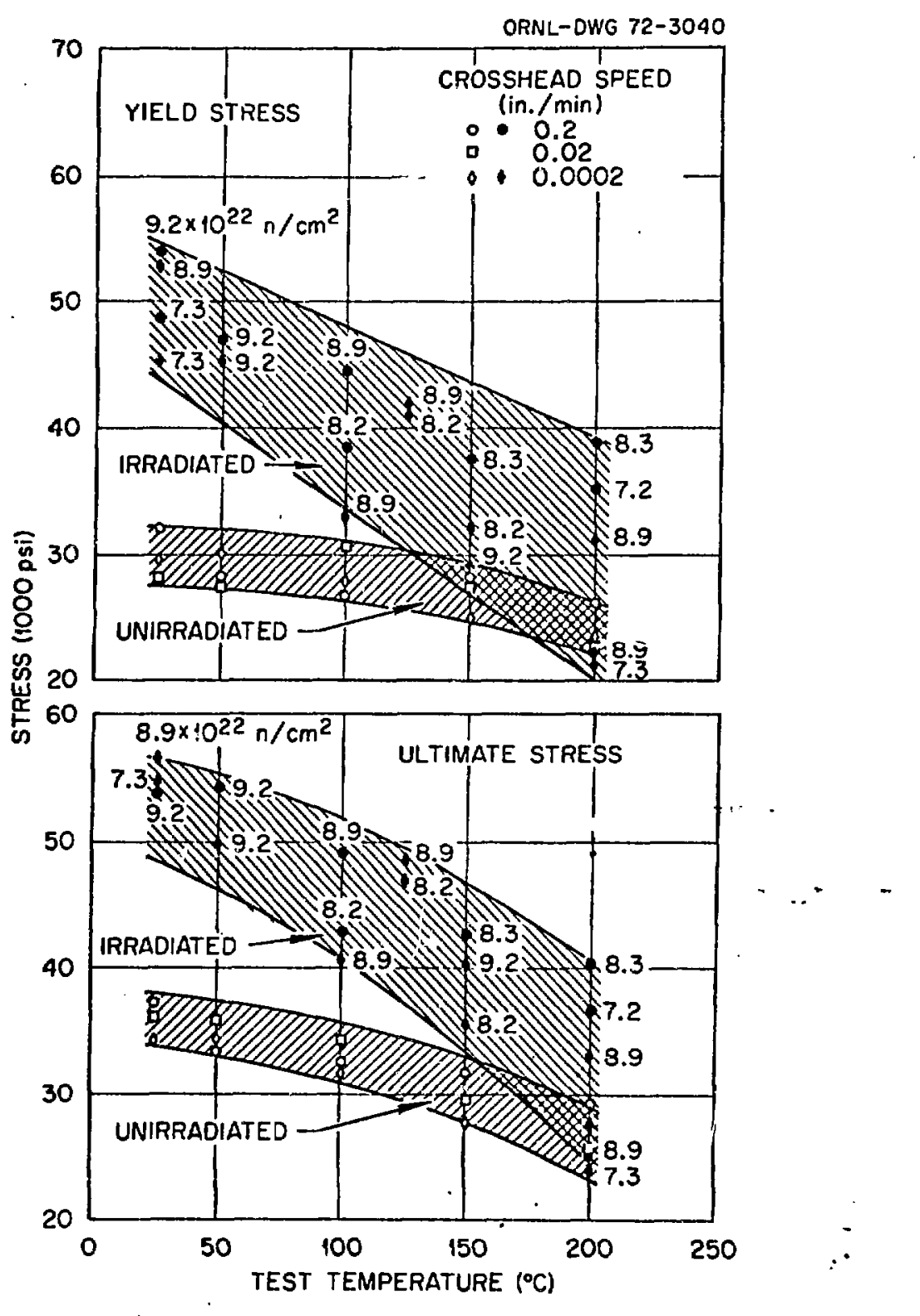

Fig. 6. Effects of irradiation, test temperature and crosshead speed on the strength of the 6061 aluminum dogbone specimens. The number next to each experimental point is the fast neutron fluence $\rightarrow 0.1 \mathrm{MeV}$ ). 


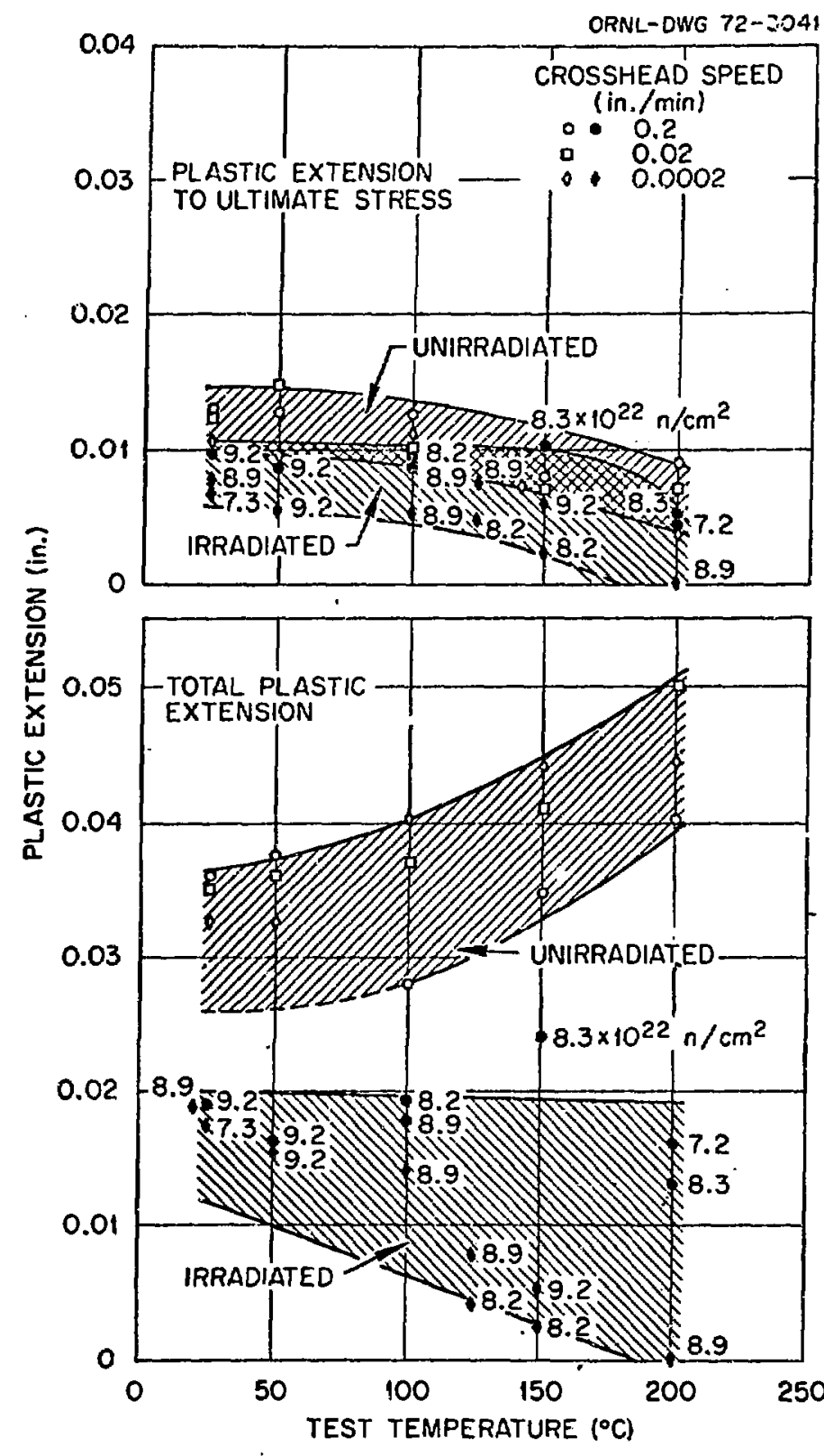

Fig. 7. Ductility of dogbone specimens from tests in Fig. 6. 